\title{
Membrane Protein Transfer from Human Erythrocyte Ghosts to Liposomes Containing an Artificial Boundary Lipid
}

\author{
By Ken-ichi Suzuki, Yukihisa Okumura, Toshinori Sato, ${ }^{\dagger)}$ and Junzo Sunamoto \\ Division of Synthetic Chemistry and Biological Chemistry, Graduate School of Engineering, \\ Kyoto University, Kyoto 606-01 \\ (Communicated by Seizo Okamura, M. J. A., March 13, 1995)
}

\begin{abstract}
When human erythrocyte ghost was exposed to a liposome that contains an artificial boundary lipid (1, 2-dimyristoylamido-1, 2-deoxyphosphatidylcholine, coded as $\mathrm{D}_{14} \mathrm{DPC}$ ), various kinds of membrane proteins and several lipids effectively transferred from the ghost to the liposome. The amount of proteins transferred increased with an increase in the $\mathrm{D}_{14} \mathrm{DPC}$ content of the liposome. The SDS-PAGE analysis revealed the bands at $88 \mathrm{kDa}, 74 \mathrm{kDa}$ and $55 \mathrm{kDa}$ in the liposome after the exposure. No erythrocyte proteins larger than $88 \mathrm{kDa}$ were detected. Transfer of $\mathrm{AChE}$ and band 3 was detected by using the enzymatic activity of $\mathrm{AChE}$ and a fluorescence probe specific to band 3 . For the membrane protein transfer, an induction period was usually observed. The duration of the induction period was almost same for both of proteins, AChE and band 3. However, the transfer efficiency of band 3 was much less than that of AChE. Except the membrane proteins, a detectable amount of cholesterol also transferred from the ghost to the liposome. On the other hand, a significant amount of phospholipids simultaneously transferred from the liposome to the ghost.
\end{abstract}

Key words : Artificial boundary lipid; liposome; direct membrane protein transfer; acetylcholinesterase (AChE); band 3; human erythrocyte ghost.

Introduction. In 1976, Dunnik et al. found that during interaction of red blood cells, spleen cells or tumor cells with DPPC or egg PC liposomes, cell components such as phospholipids and membrane proteins were transferred from those cells to the liposomes. ${ }^{1)}$ Bouma et al. manifested that at least four membrane proteins, band $4.2,7$, acetylcholinesterase (AChE) and band 3 were transferred from human erythrocytes to DMPC liposomes. ${ }^{2)}$ They also reported that the band 3 transferred kept its anion transport activity and native orientation, ${ }^{3), 4)}$ that transfer of AChE was affected by the fluidity of erythrocyte and liposome membranes, ${ }^{5)}$ and that a small fraction of band 3 transferred to liposome could be re-transferred to erythrocytes ${ }^{3)}$ or lymphocytes. ${ }^{6)}$ With their procedure, however, the transfer efficiency of membrane proteins from cells to liposomes was generally too low to use in practice.

In order to make membrane proteins in liposomal

†) Present address: Department of Biomolecular Engineering, Tokyo Institute of Technology. membrane more stable, Sunamoto and his coworkers developed an artificial lipid, 1, 2-dimyristoylamido-1, 2-deoxyphosphatidylcholine $\left(\mathrm{D}_{14} \mathrm{DPC}\right.$, Fig. 1) which has amide bonds similar to sphingomyelin, a candidate of the boundary lipid in nature. ${ }^{7), 8}$

$\mathrm{D}_{14} \mathrm{DPC}$ has been shown to improve the efficiency of the protein transfer and the retention of antigenicity of transferred proteins in liposome. Membrane proteins were transferred more efficiently from erythrocytes, ${ }^{9)}$ B16 melanoma cells, ${ }^{10)}$ human platelets ${ }^{11)}$ directly to $\mathrm{D}_{14} \mathrm{DPC}$ containing liposomes than to pure DMPC liposomes. Nakamura et al. demonstrated that the protein transfer using $\mathrm{D}_{14} \mathrm{DPC}$ containing liposomes is even applicable to a tissue of a live animal by transferring taste receptors from intact epithelium of a bullfrog tongue. ${ }^{12)}$ Shibata et al. found the better tumor rejection responses of semi-syngeneic mice sensitized by liposomes reconstituted with tumor surface antigen proteins by interaction bêtween BALBRVD leukemia cells and $\mathrm{D}_{14} \mathrm{DPC}$ containing liposomes than a butanol extraction method. ${ }^{13,14)}$ These results indicate a possibility to develop a new 


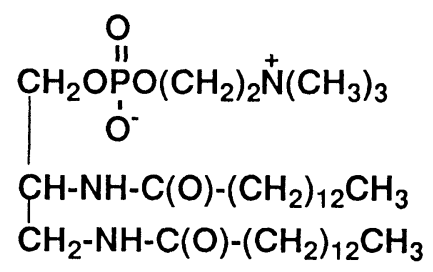

Fig. 1. Structure of artificial boundary lipid ( $\left.\mathrm{D}_{14} \mathrm{DPC}\right)$.

practical method for extraction and reconstitution of membrane proteins based on the membrane protein transfer to $\mathrm{D}_{14} \mathrm{DPC}$ containing liposomes.

The direct membrane protein transfer method has the following merits over conventional membrane protein reconstitution procedures that use detergents or organic solvents: (1) the native orientation of membrane proteins can be kept even after the transfer to liposomes ${ }^{3), 5)}(2)$ the risk of protein denaturation or deactivation is smaller ${ }^{13), 14)}$ and (3) the procedure is simple.

In order to make direct membrane protein transfer more convenient and reliable, we attempted to obtain more knowledge of factors controlling the phenomena and elucidate the mechanism. As a first step, we examined the effect of $\mathrm{D}_{14} \mathrm{DPC}$ in liposomes on the transfer of various species from erythrocyte ghosts and time course of the transfer, focusing on two morphologically different membrane proteins AChE and band 3 .

Experimental. Materials. DMPC (1, 2-dimyristoylphosphatidylcholine) (Sigma Chemical Co., St. Louis, U.S.A.), $\mathrm{D}_{14} \mathrm{DPC}$ (Dojindo Laboratories,
Kumamoto, Japan) and all other reagents were commercially available. Human red cells were kindly donated by Kyoto Red Cross Blood Center.

Preparation of liposomes and erythrocyte ghosts. Liposomes were obtained from DMPC or a mixture of DMPC and $\mathrm{D}_{14} \mathrm{DPC}$ in $10 \mathrm{mM}$ HEPES buffer containing $150 \mathrm{mM} \mathrm{NaCl}(\mathrm{pH} 7.4)$ by the extrusion method. ${ }^{15)}$ The mean diameter of the liposomes was determined as approximately $100 \mathrm{~nm}$ with narrow distribution by a dynamic light scattering measurement (DLS-70, Photal Otsuka Electronics, Hirakata, Japan). Human erythrocyte ghosts were prepared according to Dodge et al. ${ }^{16)}$ Protein transfer experiments were carried out within several days after the donation of the erythrocytes.

Interaction of erythrocyte ghosts with liposomes. Typically, $2.0 \mathrm{ml}$ of a liposomal suspension (lipid concentration, $1.0 \times 10^{-2} \mathrm{M}$ ) was coincubated at $37.0^{\circ} \mathrm{C}$ for $120 \mathrm{~min}$ with $2.0 \mathrm{ml}$ of an erythrocyte ghost suspension (protein concentration, $9.24 \mathrm{mg} / \mathrm{ml}$ ). After chilled to $0^{\circ} \mathrm{C}$, the erythrocyte ghosts and the liposomal supernatant were separated by centrifugation at $20000 \times g$ for $30 \mathrm{~min}$. The supernatant was further filtered through a Millex-PE membrane filter (pore size, $0.8 \mu \mathrm{m}$, Millipore, Tokyo, Japan) for complete separation of the liposome from the ghost. The liposomal fraction thus obtained was further characterized by gel filtration, sucrose gradient centrifugation and dynamic light scattering.

Lipid and protein analyses. The concentration of phospholipids of liposomes was assayed by using Phospholipid Test Kit (Wako Pure Chemical, Tokyo,

Table I. Proteins, phospholipids, AChE activity, band 3 and cholesterol found in liposome fractions after interaction with erythrocyte ghosts. Human erythrocyte ghosts (protein concentration, $9.24 \mathrm{mg} / \mathrm{ml}$ ) were incubated with liposome suspensions (final volume, $4.0 \mathrm{ml}$; total liposomal lipid concentration, $10 \mathrm{mM}$ ) in $10 \mathrm{mM}$ HEPES buffer containing $150 \mathrm{mM} \mathrm{NaCl}(\mathrm{pH} 7.4)$ at $37.0^{\circ} \mathrm{C}$ for 2 hours.

\begin{tabular}{lcccc}
\hline & \multicolumn{4}{c}{ Liposomes (DMPC: D $_{14}$ DPC by mol) } \\
\cline { 2 - 5 } & $100: 0$ & $80: 20$ & $60: 40$ & $40: 60$ \\
\hline Proteins (mg) & 0.89 & 1.73 & 2.64 & 3.55 \\
& {$[4.8]^{\text {a) }}$} & {$[9.3]$} & {$[14.3]$} & {$[19.2]$} \\
Phospholipids (mg) & 10.9 & 10.0 & 10.5 & 9.7 \\
& $(80.3)$ & $(74.0)$ & $(77.4)$ & $(72.0)$ \\
AChE activity & {$[9.6]$} & {$[36.5]$} & {$[51.2]$} & {$[58.7]$} \\
Band 3 & {$[3.8]$} & {$[11.6]$} & {$[17.8]$} & {$[28.0]$} \\
Cholesterol & {$[8.8]$} & {$[12.8]$} & {$[18.8]$} & {$[22.2]$} \\
\hline
\end{tabular}

a) Percentage to the amount found in the erythrocyte ghosts [ ] or the liposomes ( ) before the incubation. 
Japan). Lipid composition of liposomes after the protein transfer was analyzed by thin layer chromatography on a silica gel plate (HPTLC, Merck, Darmstadt, Germany) developed by $\mathrm{CHCl}_{3}-\mathrm{CH}_{3} \mathrm{OH}$ $\mathrm{H}_{2} \mathrm{O}$ (65:25:4 by vol.). For the detection, iodine and naphthol were used for all lipids, while ninhydrin for aminolipids. For a quantitative analysis, thin layer chromatography equipped with a flame ionization detector (IATRON, Tokyo, Japan) was employed. The concentration of cholesterol was measured according to Zlatkis et al. ${ }^{17)}$

The total amount of proteins transferred from ghosts to liposomes was estimated by the fluorescamine method. ${ }^{18)}$ The protein content of the proteoliposomes was estimated based on a calibration curve obtained for bovine serum albumin (excitation at 390 $\mathrm{nm}$ and emission at $475 \mathrm{~nm}$, Hitachi 650-10S, Tokyo, Japan). Desalted, delipidated and lyophilized liposomes were submitted to SDS-PAGE on a Phast System (Pharmacia Co., Ltd., Uppsala, Sweden), and proteins were detected by silver staining.

AChE activity of erythrocytes or liposomes was measured by the Ellman method. ${ }^{19)}$ The initial rate of AChE-catalyzed hydrolysis of acetylthiocholine was determined and used as an index of the AChE activity. The transfer of band 3 was monitored by fluorescence labeling with eosin-5-isothiocyanate (EITC). EITC is known to almost exclusively label band 3 and has been used for measuring inhibition of anion uptake and molecular motion. ${ }^{20), 21)}$ This labeling did not affect AChE transfer at all. After the interaction of EITClabeled ghosts with the liposomes, the amount of band
3 transferred to the liposomes was determined from the fluorescence intensity of the labeling EITC (excitation at $528 \mathrm{~nm}$, emission at $546 \mathrm{~nm}$ ).

Results and discussions. Analysis of membrane proteins and lipids transferred from erythrocyte ghosts to liposomes. After coincubation of erythrocyte ghost with the DMPC (40 mol\%) / $\mathrm{D}_{14} \mathrm{DPC}(60 \mathrm{~mol} \%)$ liposome, gel filtration of the liposomal supernatant obtained revealed that all proteins were bound to the liposome and no soluble proteins were contained in this fraction. Further analysis by sucrose density gradient centrifugation showed that the liposomal supernatant was totally free from cell fragments. These results indicate that all the proteins found in the liposomal supernatant were those transferred from the ghosts to the liposomes.

The size of liposome remained unchanged before and after the interaction, indicating that the liposome is stable during the transfer procedure. Even three weeks after the exposure to erythrocyte ghosts, the liposomes were quite stable and no precipitation was found.

An increase in the $\mathrm{D}_{14} \mathrm{DPC}$ content of the DMPC liposomes increased the total amount of membrane proteins transferred (Table I). Compared with the DMPC liposomes, the $\operatorname{DMPC}(40) / \mathrm{D}_{14} \mathrm{DPC}(60)$ liposome could extract four times more membrane proteins.

Fig. 2 shows SDS-PAGE analysis of the transerred erythrocyte membrane proteins. The band at 88 $\mathrm{kDa}$ was stained more significantly in liposome containing more $\mathrm{D}_{14} \mathrm{DPC}$. The band at $74 \mathrm{kDa}$ was able to

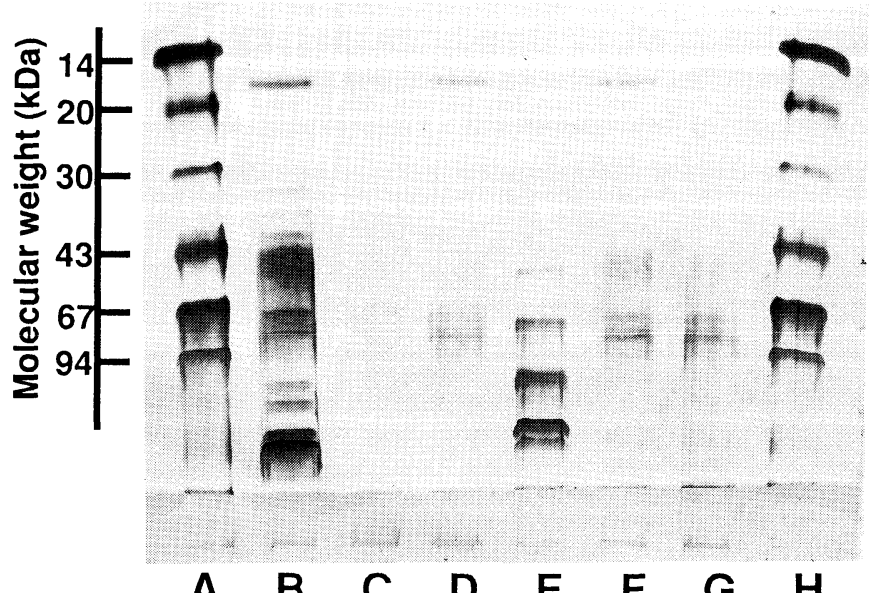

Fig. 2. SDS-PAGE analysis of erythrocyte ghost proteins. Lanes A and H, low molecular weight markers; B, erythrocyte ghost membrane; C, D, F and G, liposome fractions after incubation with erythrocyte ghosts (C, DMPC(100); D, DMPC $(80) / \mathrm{D}_{14} \mathrm{DPC}(20)$; F, $\mathrm{DMPC}(60) / \mathrm{D}_{14} \mathrm{DPC}(40) ; \mathrm{G}, \mathrm{DMPC}(40) / \mathrm{D}_{14} \mathrm{DPC}(60)$; $\mathrm{E}$, high molecular weight markers. 

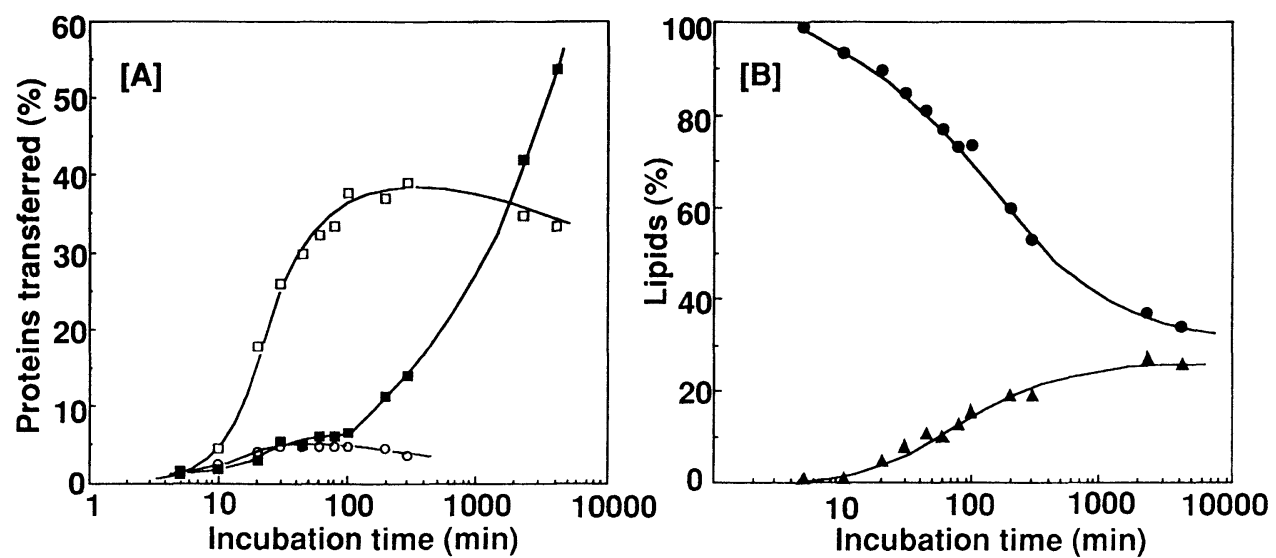

Fig. 3. Time course of protein transfer [A] (- - - band 3; - - - , total proteins; and - $\square$ - AChE), and the amount of lipids in the liposomal supernatant $[\mathrm{B}](-\mathbf{\Delta}-$, cholesterol; and $-\mathbf{-}$, total phospholipids). DMPC(40)/D ${ }_{14} \mathrm{DPC}(60)$ liposome was used.

be assigned to band 4.2. ${ }^{22)}$ These two bands were very weak for the case of the DMPC liposome. The band around $55 \mathrm{kDa}$ seen in $\mathrm{DMPC}(60) / \mathrm{D}_{14} \mathrm{DPC}(40)$ and $\mathrm{DMPC}(40) / \mathrm{D}_{14} \mathrm{DPC}(60)$ liposomes is probably band 4.5. ${ }^{22)}$ The SDS-PAGE analysis revealed that proteins having higher molecular weight than band 3 , for example spectrin, were not found. This result was in agreement with the previous report of Bouma et al. ${ }^{2}$

Sunamoto and his coworkers reported that membrane proteins transferred from B16 melanoma changed when the $\mathrm{D}_{14} \mathrm{DPC}$ content of the liposomes or the culture system was altered. ${ }^{10)}$ On the other hand, Okumura et al. found no significant selectivity in the transfer of membrane proteins from human platelet. ${ }^{11)}$ At present, the selectivity of proteins in the direct transfer seems to be largely dependent on cells and, therefore, still difficult to generalize for all cell types.

The AChE activity transferred also was shown in Table I. The activity of a mixture of liposomes and erythocyte ghosts after the incubation for $120 \mathrm{~min}$ was equal to that of the original erythrocyte ghosts (data not shown), indicating that the activity of AChE did not change at all even after the protein transfer. The DMPC (40)/ $\mathrm{D}_{14} \mathrm{DPC}(60)$ liposome showed approximately six times higher activity than the DMPC liposome. Approximately $60 \%$ of the original activity on erythrocytes was kept on the DMPC $(40) / \mathrm{D}_{14} \mathrm{DPC}(60)$ liposome nevertheless only $20 \%$ of the total proteins was transferred. The transfer efficiency of band 3 was less than that of $\mathrm{AChE}$; at most $28 \%$ with $\mathrm{DMPC}(40) /$ $\mathrm{D}_{14} \mathrm{DPC}(60)$. The DMPC(40)/ $\mathrm{D}_{14} \mathrm{DPC}(60)$ liposome extracted band 3 seven times more than the DMPC liposome.
The difference in the transfer efficiency between $\mathrm{AChE}$ and band 3 can be attributed to the structural difference between the two. AChE $(75 \mathrm{kDa})$ exists as the dimer and binds to erythrocyte membrane via a phosphatidylinositol lipid anchor. ${ }^{23)}$ Band $3(88 \mathrm{kDa})$ also exists as the dimer and has twelve-membrane spanning domains in erythrocyte membrane interacting with peripheral proteins such as band 4.2 and ankyrin. ${ }^{24), 25)}$ Therefore, more loosely bound $\mathrm{AChE}$ might be more easily extracted.

Other than membrane proteins, a significant amount of cholesterol was also transferred to liposome accompanied by the protein transfer (Table I). In the case of DMPC $(40) / \mathrm{D}_{14} \mathrm{DPC}(60), 22 \%$ of cholesterol was transferred from erythrocyte ghosts, and the amount was approximately 2.5 times larger than that observed for the DMPC liposome. Other lipids such as phosphatidylethanolamine, phosphatidylserine and glycolipids were barely seen (less than $0.5 \%$ of the total lipids).

The total amount of phospholipids found in the liposomal supernatants became less after the coincubation with ghosts. Meanwhile, the total lipid content of the ghost increased after the coincubation, and the two values were coincident and balanced well, suggesting that a part of phospholipids certainly transferred from the liposome to the ghost during the coincubation between the two.

Time course of the transfer of AChE, total proteins and band 3. Cook et al. has reported that an induction period existed before the AChE transfer from erythrocyte to DMPC liposome. ${ }^{5)}$ We found the existence of an induction period also in the band 3 transfer, and the induction periods for AChE, total 
proteins and band 3 were almost same (Fig. 3A). Furthermore, the transfer of AChE and band 3 reached a plateau at almost the same time. Considering the structure of two proteins being quite different each other, it is unlikely that the initiation and the termination of the transfer were due to the proteins themselves. Therefore, it should be assumed that the initiation and the termination of the membrane protein transfer is regulated by other factors such as structural change of cell membrane.

The significant increase of the total protein after the extended incubation ( $>$ approx. $2 \mathrm{hr}$ ) may be mostly due to transfer of peripheral proteins, because the amount of integral proteins other than AChE and band $3^{22)}$ is too small to account the phenomena.

Fig. 3B shows the transfer of cholesterol from the erythrocyte ghosts to the liposomes and that of phospholipids in the other direction, which is accompanied by the protein transfer.

Conclusion. $\mathrm{D}_{14} \mathrm{DPC}$ enhanced the transfer efficiency of various membrane components of erythrocyte to liposome. The transfer efficiency of AChE was much higher than that of band 3 as expected from the large morphological difference between the two proteins. However, the initiation and the termination of the transfer were almost the same for the two, indicating that a major factor to control the protein transfer may come from the matrices of cell membrane. We could show here the mechanical elucidation of the membrane protein transfer and will pursue further details of the phenomena in order to achieve the completely specific membrane protein transfer.

Acknowledgments. The authors are grateful to Dr. Manabu Oki, Kyoto Red Cross Blood Center, for the donation of concentrated erythrocytes. This research was supported by Grant-in-Aid for Scientific Research on Priority Areas from Ministry of Education, Science and Culture (No. 04204021).

\section{References}

1) Dunnik, J. K., Rooke, J. D., Aragon, S., and Kriss, J. P. (1976) Cancer Res. 36, 2385-2389.

2) Bouma, S. R., Drislane, F. W., and Huestis, W. H. (1977) J. Biol. Chem. 252, 6759-6763.

3) Newton, A. C., Cook, S. L., and Huestis, W. H. (1983) Biochemistry 22, 6110-6117.

4) Huestis, W. H., and Newton, A. C. (1986) J. Biol. Chem.
261, 16274-16278.

5) Cook, S. L., Bouma, S. R., and Huestis, W. H. (1980) Biochemistry 19, 4601-4607.

6) Newton, A. C., and Huestis, W. H. (1988) Biochemistry 27, 4655-4659.

7) Sunamoto, J., Goto, M., Iwamoto, K., Kondo, H., and Sato, T. (1990) Biochim. Biophys. Acta 1024, 220-226.

8) Goto, M., Arakawa, M., Sato, T., Kondo, H., and Sunamoto, J. (1987) Chem. Lett. 1987, 1935-1938.

9) Sunamoto, J., Goto, M., and Akiyoshi, K. (1990) Chem. Lett. 1990, 1249-1252.

10) Sunamoto, J., Mori, Y., and Sato, T. (1992) Proc. Japan Acad. 68 B, 69-74.

11) Okumura, Y., Ishitobi, M., Sobel, M., Akiyoshi, K., and Sunamoto, J. (1994) Biochim. Biophys. Acta 1194, 335340 .

12) Nakamura, M., Tsujii, K., Katsuragi, Y., Kurihara, K., and Sunamoto, J. (1994) Biochem. Biophys. Res. Commun. 201, 415-422.

13) Shibata, R., Noguchi, T., Sato, T., Akiyoshi, K., Sunamoto, J., Shiku, H., and Nakayama, E. (1991) Int. J. Cancer. 48, 434-442.

14) Sunamoto, J., Noguchi, T., Sato, T., Akiyoshi, K., Shibata, R., and Nakayama, E. (1992) J. Controlled Release 20, 143-153.

15) Olson, F., Hunt, C. A., Szoka, F. C., Vail, W. J., and Papahadjopoulos, D. (1979) Biochim. Biophys. Acta 557, 9-23.

16) Dodge, J. T., Mitchell, C., and Hanahan, D. J. (1963) Arch. Biochem. Biophys. 100, 119-130.

17) Zlatkis, A., Zak, B., and Boyle, A. J. (1953) J. Lab. Clin. Med 41, 486-492.

18) Udenfriend, S., Stein, S., Bölen, P., Dairman, W., Leimgraber, W., and Weigele, W. (1972) Science 178, 871872.

19) Ellman, J. L., Coutney, K. D., Andres, V. Jr., and Fetherstone, R. M. (1961) Biochem. Pharmacol. 7, 88-95.

20) Cherry, R. J., Cogoli, A., Oppliger, M., Schneider, G., and Semenza, G. (1976) Biochemistry 15, 3653-3656.

21) Cherry, R. J., and Schneider, G. (1976) Biochemistry 15, $3657-3661$.

22) Haest, C. W. M. (1982) Biochim. Biophys. Acta 694, 331352.

23) Roberts, W. L., Santikarn, S., Reinhold, V. N., and Rosenberry, T. L. (1988) J. Biol. Chem. 263, 1877618784 .

24) Kopito, R. R., and Lodish, H. F. (1985) Nature 316, 234238.

25) Korsgren, C., and Cohen, C. M. (1986) J. Biol. Chem. 261, $5536-5543$. 